\title{
ESTAQUIA DE PARIPAROBA-DO-RIO GRANDE DO SUL SOB EFEITO DO ÁCIDO INDOL-BUTÍRICO EM DOIS SUBSTRATOS
}

\section{CUTTINGS OF PARIPAROBA-DO RIO GRANDE DO SUL USING INDOL BUTIRIC ACID IN TWO SUBSTRATES}

\author{
Rosete PESCADOR ${ }^{1}$ \\ Ana Carolina VOLTONI ${ }^{2}$ \\ Carla Giovana GIRARDI ${ }^{3}$ \\ Flávia Aparecida Fernandes da ROSA ${ }^{1}$
}

\begin{abstract}
RESUMO
No presente trabalho foram avaliados o efeito de quatro concentrações de ácido indol butírico AIB $(0,500,1000$ and $1500 \mathrm{mg} \mathrm{L}^{-1}$ ) e dois substratos (areia e vermiculita) na estaquia de Pariparoba-do-Rio Grande do Sul [Piper mikanianum (KUNTH) Steud var. Mikanianum (Piperaceae)]. O experimento baseou-se no delineamento experimental inteiramente casualizado, constando de 15 repetições composta de 30 estacas por tratamento. Verificou-se que o AlB possui efeito no que se refere ao índice de sobrevivência das estacas, independente do substrato utilizado, areia ou vermiculita. Os resultados sugerem que estacas cultivadas no substrato constituído por vermiculita são capazes de formar maior número de folhas, raízes e brotações, cujos valores são proporcionais ao aumento da concentração de AlB, devido a boa retenção de água e ótimo espaço de ar na capacidade de retenção, fatores que the possibilitam a manutenção de um adequado suprimento de água para o enraizamento de estacas.

Palavras-chave: areia; vermiculita; enraizamento; Piper mikanianum.
\end{abstract}

\begin{abstract}
This work was made to study the effect two different substrate (sand and vermiculite) and four concentration ( 0 , 500,1000 and $1500 \mathrm{mg} \mathrm{L}^{-1}$ ) indol butyric acid IBA on the cutting of "Pariparoba-do-Rio Grande do Sul" [Piper mikanianum (KUNTH) Steud var. Mikanianum (Piperaceae)]. The experiments were basal, randomly distributed in 15 repetitions of 30 cutting for treatment. It was detected for AIB was affected survival rate independ to used substrate, sand or vermiculite. The results suggest that cutting cultivated in sand substrate are capable to form bigger number of roots with lesser concentration of AIB due to bigger aeration, in detriment of those composed by in corporate substrate for vermiculite. Because there was water retention and excellent air space in the maintenances of adequate water supplement for the rooting of cuttings.

Key-words: sand; vermiculite; rooting; Piper mikanianum.
\end{abstract}

\footnotetext{
${ }^{1}$ Eng. Agrônoma, Dra. em Botânica, Universidade de São Paulo - USP, Docente do Departamento de Ciências Naturais - DCN, Universidade Regional de Blumenau - FURB. Email: rosetp@furb.br.

${ }^{2}$ Eng. Florestal, Departamento de Engenharia Florestal - DEF, Universidade Regional de Blumenau - FURB.

${ }^{3}$ Graduanda Ciências Biológicas, Bolsista PIBIC/CNPq, Departamento de Ciências Naturais - DCN, Universidade Regional de Blumenau FURB, Rua Antônio da Veiga, 140, Caixa Postal 1507, 89010-971, Blumenau, SC.

${ }^{4}$ Química, Dra. em Química Orgânica, Universidade Federal de Santa Catarina - UFSC, Docente do Departamento de Química - DQ, Universidade Regional de Blumenau - FURB.
} 


\section{INTRODUÇÃO}

O desenvolvimento da clonagem de espécies vegetais através da estaquia foi o marco inicial para a propagação vegetativa assumir posição de destaque e despertar o interesse das empresas e pesquisadores, com conseqüente busca de aprimoramentos e inovações tecnológicas.

A melhoria no enraizamento de estacas tem sido alcançada através de técnicas como a miniestaquia (WENDLING et al., 2000), que possibilita considerável ganho decorrente do aumento dos índices de raízes e da redução do tempo para formação da muda.

Aplicações exógenas de auxinas em estacas proporcionam maior porcentagem, velocidade, qualidade e uniformidade de enraizamento (HARTMANN et al., 1997). Dentre as auxinas mais conhecidas e utilizadas no enraizamento de estacas, têm-se o ácido indolacético (AIA), o ácido indolbutírico (AIB), o ácido naftaleno acético (ANA) e o 2,4-diclorofenoxiacético (2,4-D) (BLAZICH, 1987). As concentrações do produto ativo variam com o genótipo (CHUNG e LEE, 1994), o estado de maturação do propágulo (GOMES, 1987) e a forma de aplicação, que pode ser via solução aquosa ou via sólida com o uso de talco (BLAZICH, 1987).

Dentre as auxinas sintéticas mais eficientes em promover o enraizamento de estacas, o AIB vem sendo efetivo para um grande número de plantas, por ser estável a fotodegradação, imune a ação biológica e possuir boa capacidade de promover o enraizamento, e tem sido utilizado em estacas de várias espécies, principalmente aquelas que apresentam dificuldades em emitir raízes, promovendo, assim, a diferenciação celular e a formação de raízes (TONIETTO et al., 1997).

Outro fator importante no processo de estaquia é a utilização do substrato, os melhores substratos devem apresentar, entre outras características, ausência de patógeno, riqueza em nutrientes essenciais, textura e estrutura adequadas (SILVA et al., 2001). HOFFMANN et al. (2001) afirmam que o substrato é um dos fatores de maior importância no enraizamento de estacas.

A Piper mikanianum (KUNTH) Steud var. mikanianum (Piperaceae), popularmente denominada de jaguarandi ou pariparoba-do-Rio Grande do Sul (GUIMARÃES e VALENTE, 2002), possui como componente majoritário no óleo essencial, o safrol, equivalendo a $82 \%$ do mesmo (ABREU et al., 2002). Esta característica aliada ao fato de ser um arbusto com crescimento rápido coloca esta espécie como possível substituta para a canela sassafrás.

Assim, devido à falta de informações e conhecimento sobre a propagação de $P$. mikanianum, esse trabalho teve por objetivo avaliar o efeito dos substratos e do AIB no processo de propagação, importante para a domesticação da espécie.

\section{MATERIAL E MÉTODOS}

Foram utilizadas estacas de Piper mikanianum provenientes de ramos com tamanho médio de $12 \pm 3 \mathrm{~cm}$, retirados da porção mediana das plantas, de altura média de $1 \mathrm{~m}$, coletadas no mês de setembro de 2005, as quais apresentavam com boa qualidade fitossanitária. Foram coletadas na sede da APREMAVI (Associação de Preservação do Meio Ambiente do Alto Vale do Itajaí) situada no

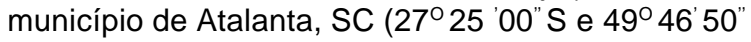
W).

Duzentas e quarenta estacas foram cortadas em bisel simples na base retirando-se as folhas. Suas bases foram imersas por 1 minuto em solução aquosa de AIB, sendo este regulador previamente dissolvido com 5 gotas de $\mathrm{KOH} 1 \mathrm{~mol} \mathrm{~L}^{-1}$, nas concentrações de $500 \mathrm{mg} \mathrm{L}^{-1}, 1000 \mathrm{mg} \mathrm{L}^{-1}$ e 1500 $\mathrm{mg} \mathrm{L}^{-1}$ incluindo um tratamento testemunha. Após a imersão, foram colocadas 2 estacas por vaso, com capacidade para $1 \mathrm{~L}$, contendo dois tipos de substrato - vermiculita e areia, mantidos em casa de vegetação com controle automático de irrigação por aspersão e temperatura de $25 \pm 5^{\circ} \mathrm{C}$.

$\mathrm{O}$ experimento constou de um bifatorial $(4 \mathrm{x}$ 2 ), cujos tratamentos foram dois tipos de substratos e quatro concentrações de AIB. O delineamento experimental foi inteiramente casualisado, com 15 repetições, sendo que cada repetição era representada por duas estacas, perfazendo um total de 30 estacas por tratamento.

Após cento e vinte dias do início do experimento, foram coletados dados referentes ao índice de sobrevivência, número médio de folhas, número médio de raízes, comprimento médio das raízes, número médio de brotações e comprimento médio das brotações. No término das avaliações, os dados foram submetidos à análise de variância, utilizando-se o teste F. Nos casos de diferenças significativas, as médias foram comparadas pelo teste de Tukey, ao nível de $5 \%$ de probabilidade de erro.

\section{RESULTADOS E DISCUSSÃO}

De acordo com os resultados apresentados na Tabela 01, verifica-se que as estacas de Piper mikanianum, colocadas em substrato constituído por areia apresentaram percentual de sobrevivência de $63,33 \%$, quando tratadas com $1000 \mathrm{mg} \mathrm{L}^{-1}$ de AIB, sendo que os resultados observados nas estacas submetidas aos tratamentos de $0 \mathrm{mg} \mathrm{L}^{-1}$ e $500 \mathrm{mg} \mathrm{L}^{-1}$ foram de aproximadamente $20 \%$. Por outro lado, as estacas mantidas em substrato constituído por vermiculita, apresentaram um percentual de sobrevivência de $63,33 \%$ quando tratadas com $1500 \mathrm{mg} \mathrm{L}^{-1}$. Contudo, as estacas não tratadas apresentaram um índice de mortalidade de $73,33 \%$. 
TABELA 01 - Efeito da interação dos substratos (areia e vermiculita) na porcentagem de enraizamento de estacas de Piper mikanianum tratadas com diferentes concentrações de AIB.

\begin{tabular}{ccc}
\hline AlB & \multicolumn{2}{c}{ Substratos } \\
\cline { 2 - 3 }$\left(\mathrm{mg} \mathrm{L}^{-1}\right)$ & Areia & Vermiculita \\
\hline 0 & $20,02 \mathrm{~b}$ & $24,75 \mathrm{~b}$ \\
500 & $20,15 \mathrm{~b}$ & $60,05 \mathrm{a}$ \\
1000 & $63,30 \mathrm{a}$ & $31,05 \mathrm{c}$ \\
1500 & $30,06 \mathrm{c}$ & $65,00 \mathrm{a}$ \\
\hline C.V. (\%) & 20,02 & 22,9
\end{tabular}

Médias seguidas pela mesma letra na coluna não diferem significativamente pelo teste de Tukey a $5 \%$ de probabilidade de erro.

Trabalhos de RAMOS et al. (2003), com Prunus cerasifera, remetem a um índice maior de enraizamento em estacas submetidas ao substrato constituído por vermiculita quando comparadas com as enraizadas em substrato constituído por areia. Segundo HARTMANN et al. (1997), a vermiculita destaca-se entre os demais substratos no enraizamento de estacas devido à porosidade $e$ retenção de água que a caracterizam.

Para ALVARENGA e CARVALHO (1983) concordando com LOACH (1988), a elevação na concentração de auxina produz um efeito estimulador de raízes nas estacas até um ponto máximo, a partir do qual qualquer acréscimo pode ser inibitório ao enraizamento, o pode explicar a diminuição do percentual de sobrevivência das estacas no presente trabalho.

Ainda segundo, MENDONÇA et al. (2002) observaram que nas estacas de Theobroma grandiflorum tratadas com concentrações superiores a $4000 \mathrm{mg} \mathrm{L}^{-1}$ de AIB ocorria um declínio no percentual de estacas sobreviventes, mas que, mesmo assim, o percentual de sobrevivência foi relativamente alto, independente da concentração de AIB utilizada, cuja a média geral, segundo os autores, de todas as concentrações utilizadas foi de $82,5 \%$. Verificaram, assim, que a dosagem ótima de AIB varia de acordo com a espécie e também com a variedade, considerado então, genótipo dependente. Portanto, dependendo do material vegetal, o teor e o tipo de regulador de crescimento utilizados, tem-se respostas distintas no que se refere à formação de raízes, brotações e outros parâmetros, o que foi verificado nas estacas de Piper mikanianum, objeto do presente estudo.

As estacas de Piper mikaniaum tratadas com AIB nas concentrações de $1000 \mathrm{mg} \mathrm{L}^{-1}$ e $1500 \mathrm{mg} \mathrm{L}$ ${ }^{1}$ mantidas no substrato constituído de areia (Figura $1 \mathrm{~A})$, apresentaram um número médio de folhas de 2,9 e 5, respectivamente. Por outro lado, as estacas tratadas com $500 \mathrm{mg} \mathrm{L}^{-1}$ e $1000 \mathrm{mg} \mathrm{L}^{-1}$ de AIB, mantidas no substrato vermiculita, formaram em média 5 e 5,9 folhas por estaca, respectivamente cujo valor foi superior aos verificados nas estacas submetidas aos demais tratamentos, que formaram em média cerca de 3 folhas por estaca, no substrato constituído por vermiculita. O número médio de folhas por estaca de $P$. mikanianum foi afetado de forma significativa no que se refere ao efeito do tratamento substrato e concentrações de AIB. 
(A)

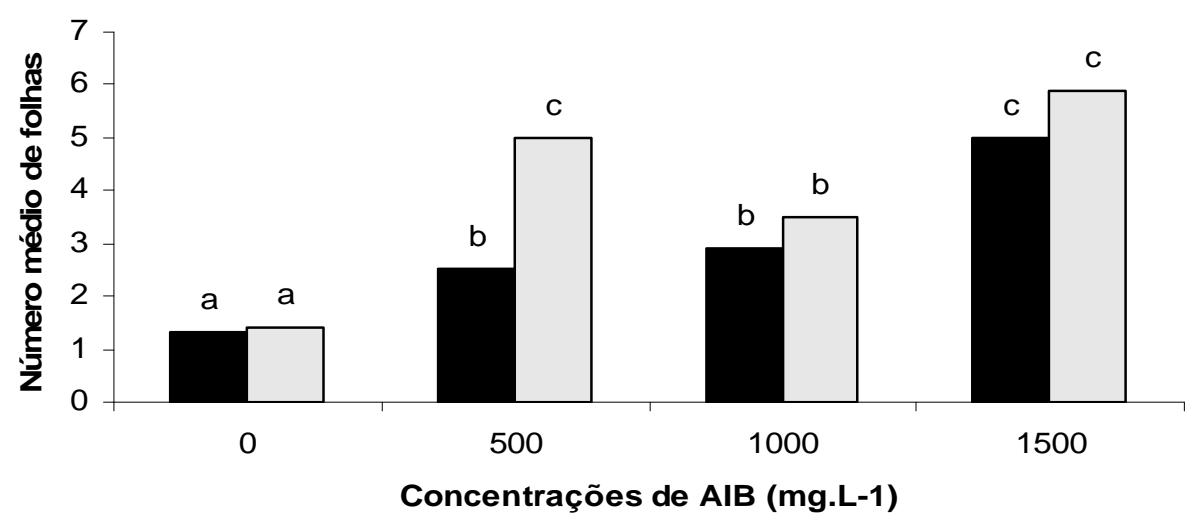

(B)

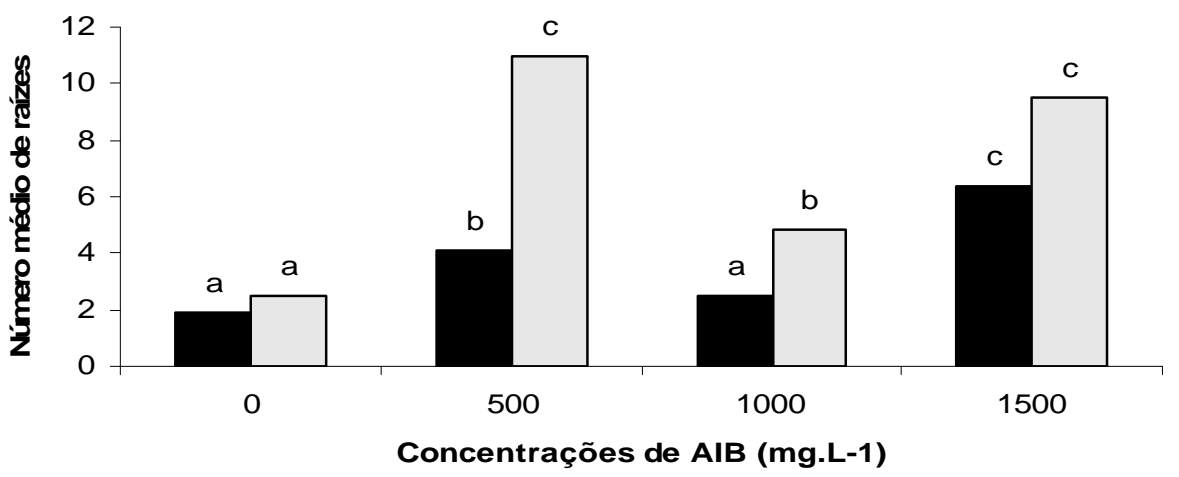

- Areia $\square$ Vermiculita

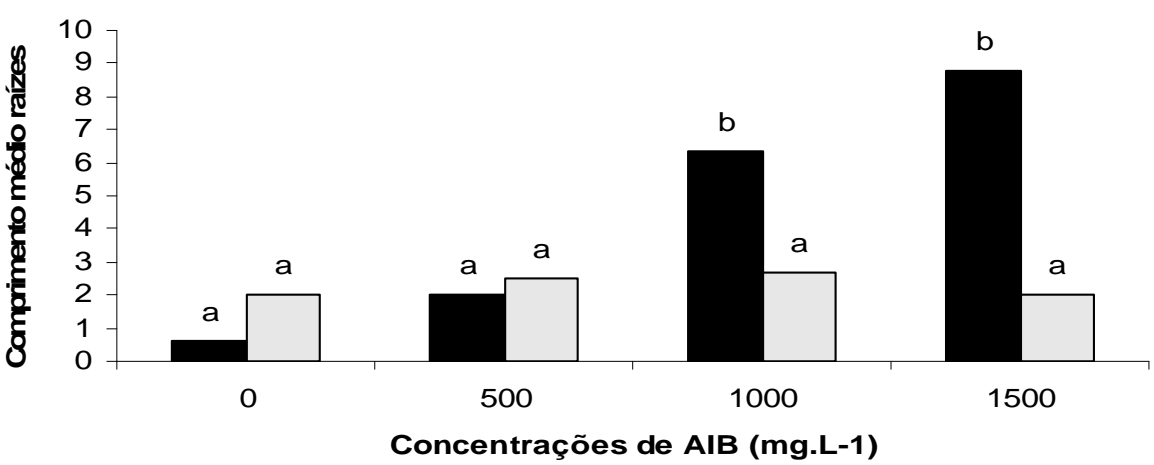

- Areia $\square$ Vermiculita

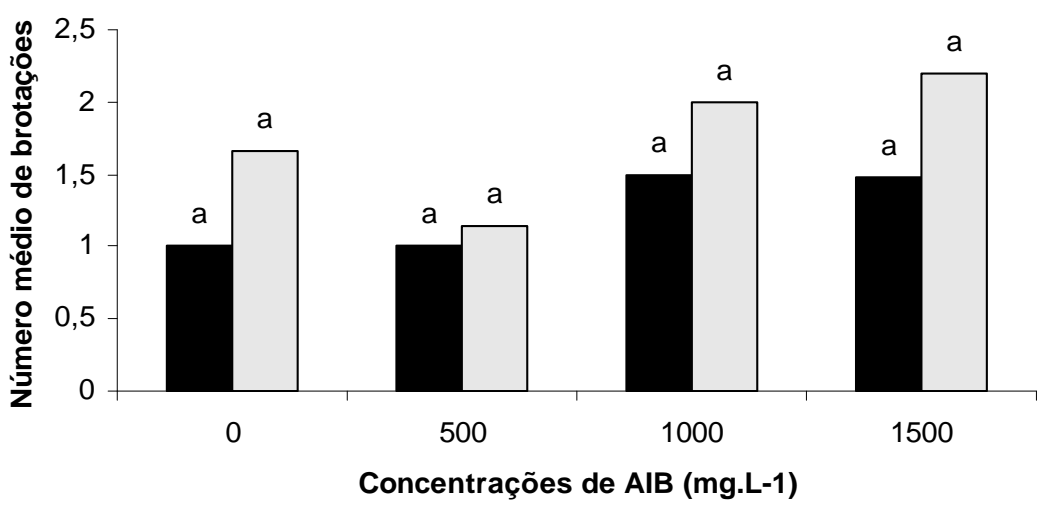

- Areia $\square$ Vermiculita

FIGURA 1 - Estaquia de Piper mikanianum tratadas com diferentes concentrações de AIB no substrato constituído por areia e no constituído por vermiculita: em A, B e D Número médio de folhas, raízes e brotações, respectivamente; e C e E comprimento médios de raízes e brotações, respectivamente. Médias seguidas pela mesma letra não diferem entre si, pelo teste Tukey a $5 \%$ de probabilidade de erro dentro de cada substrato. 


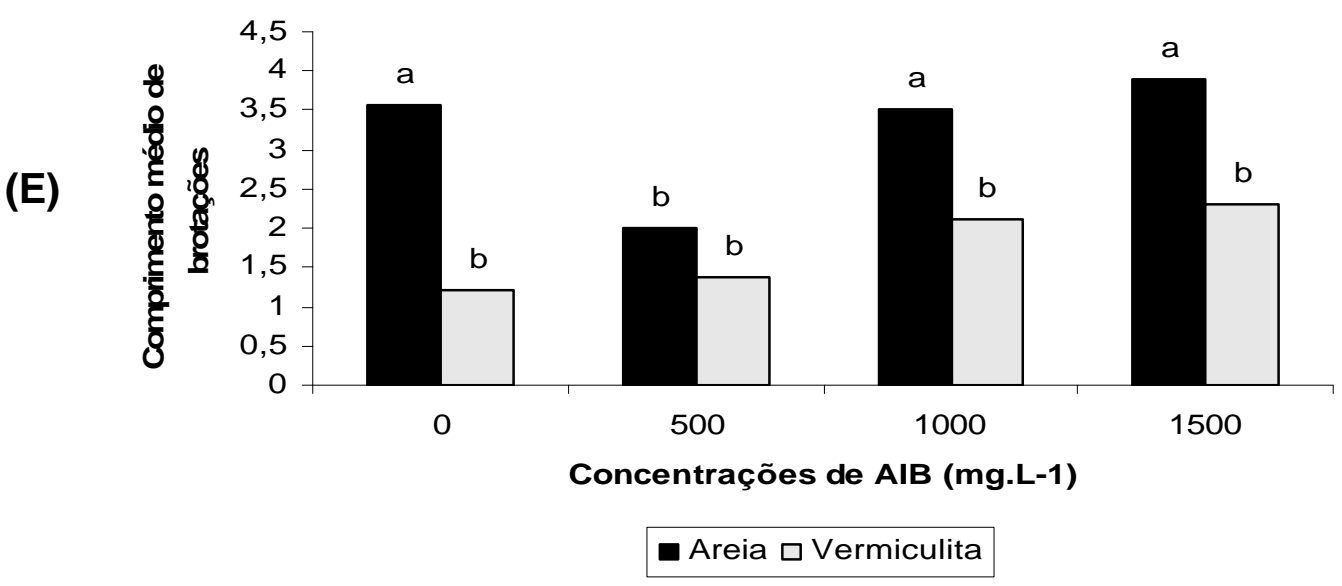

FIGURA 1 - (CONTINUAÇÃO) Estaquia de Piper mikanianum tratadas com diferentes concentrações de AIB no substrato constituído por areia e no constituído por vermiculita: em A, B e D Número médio de folhas, raízes e brotações, respectivamente; e $\mathrm{C}$ e $\mathrm{E}$ comprimento médios de raízes e brotações, respectivamente. Médias seguidas pela mesma letra não diferem entre si, pelo teste Tukey a $5 \%$ de probabilidade de erro dentro de cada substrato.

Sabendo que diferentes teores hormonais são capazes de levar à mudança de indução foliar, no que se refere ao tamanho e número de folhas por estaca, como o que aconteceu nas plântulas micropropagadas do porta-enxerto de macieira (Malus sylvestris) variedade M7, em que VOLTOLINI et al. (2002) cujos autores observaram maior formação de folhas através do tratamento na concentração de $9 \mu \mathrm{M}$ de AIB num período de 3 ou 9 dias de indução. O mesmo ocorreu em relação à utilização de substratos diferentes, a exemplo do que observaram EHLERT et al. (2004) em estacas de alfavaca-cravo (Ocimum gratissimum): uma interação significativa entre o tipo de estaca e o substrato utilizado, com destaque para o substrato formado por $20 \%$ de arisco + esterco, $40 \%$ de vermiculita e $40 \%$ de húmus. Porém, não diferiu significativamente das combinações com arisco + esterco $40 \%$ + húmus $20 \%$ + vermiculita $40 \%$ e arisco + esterco $40 \%+$ húmus $40 \%$ + vermiculita $20 \%$, resultados estes semelhantes aos obtidos neste trabalho.

As diferentes concentrações de AIB influenciaram, de forma significativa a formação de raízes em estacas de $P$. mikanianum, tanto aquelas mantidas em substrato constituído por areia, quanto às mantidas em substrato constituído por vermiculita (Figura 2 A e B). Além das diferenças na composição dos substratos, o que pode ter conduzido a este resultado foi o fato de que a auxina sensibiliza uma proteína receptora de membrana celular de alta afinidade denominada ABP1(auxin-binding-protein 1), que poderia estar presente nas células desta espécie vegetal, a qual percebe a presença do regulador e se associa a uma outra proteína também da membrana plasmática, sendo capaz de propagar o sinal hormonal para o interior da célula, cujos níveis de auxinas são baixos, comparativamente ao aplicado exógenamente, causando, assim o alongamento celular. A sequência de informações do sinal ocorre provavelmente pela presença de um outro receptor, no citossol celular, denominado genericamente por $\mathrm{Rx}$, (receptor $\mathrm{X}$ ) o qual agiria sobre a divisão celular, sob influência de concentrações mais elevadas desse hormônio
(KERBAUY, 2004), levando a formação de raízes. O efeito dos reguladores de crecimento ou hormônios vegetais depende do tipo, quantidade e dos receptores de membrana presentes nas células, cujo efeito dará a resposta final, que é, a formação ou não de raízes adventícias em estacas.

Nota-se na Figura 1B, que 0 desenvolvimento das raízes em estacas da Piper mikanianum foi influenciado significativamente pelo substrato utilizado, sendo que estacas mantidas no substrato constituído por vermiculita apresentaramse com números médios de raízes superiores em todas as concentrações de AIB comparativamente as estacas submetidas ao substrato areia, corroborando com trabalhos executados por TILLMANN et al. (1994) observando o efeito de sete substratos diferentes no enraizamento de estacas de Codiaeum variegatum, indicam a vermiculita como melhor substrato, pela boa retenção de água e ótimo espaço de ar na capacidade de retenção, fatores que lhe possibilitam a manutenção de um adequado suprimento de água para o enraizamento de estacas. Na mesma direção MIRANDA et al. (2003), avaliando o enraizamento de estacas lenhosas de pessegueiro, obtiveram baixos índices de enraizamento quando utilizaram o substrato constituído por areia, o que, segundo NACHTIGAL et al. (1994), pode estar relacionado com a resistência mecânica ao desenvolvimento das raízes proporcionada por este substrato.

O número médio de raízes formadas na base das estacas de $P$. mikanianum nas concentrações de $500 \mathrm{mg} \mathrm{L}^{-1}$ de AIB, apresentaram um valor de 11 raízes em média, nas estacas mantidas na areia (Figura 1B). Quando utilizado 1500 $\mathrm{mg} \mathrm{L}^{-1}$ de AIB em estacas mantidas no substrato constituído por vermiculita, o valor foi de 9,5 raízes por estaca. Altos teores de auxina foram capazes de estimular a formação de raízes adventícias em estacas $P$. mikanianum, como já observado em outras espécies na literatura (TAIZ e ZEIGER, 1995). Tal fato pode ser o responsável pelo surgimento de maior quantidade de raízes nas estacas tratadas com AIB. 


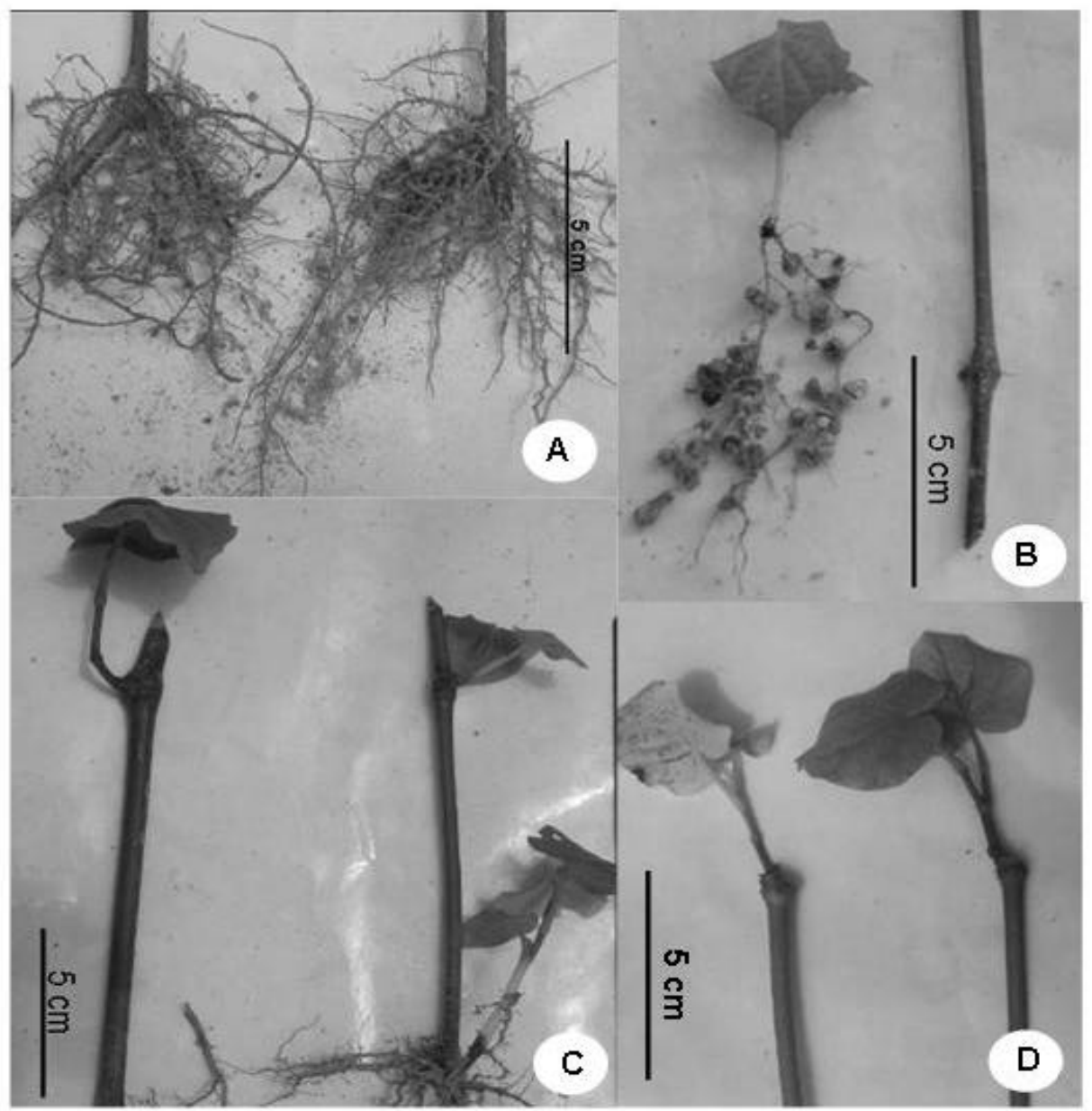

FIGURA 2 - Aspecto geral das estacas de Piper mikanianum, sendo: (A) desenvolvimento das raízes em substrato constituído por areia e (B) em substrato constituído por vermiculita; (C) aspectos das brotações em substrato constituído por areia e (D) em substrato constituído por vermiculita.

O efeito benéfico da aplicação de AIB foi verificado em estacas de ameixeira (Prunus salicina) por TONIETTO et al. (2001). Estacas da cultivar Pluma 7 apresentou um aumento significativo no número de raízes por estaca, passando de 1,6 na ausência de tratamento por reguladores de crescimento para 4,2 raízes em estacas tratadas com $2000 \mathrm{mg} \mathrm{L}^{-1}$ de AIB, sendo seu percentual de enraizamento de $99 \%$ (TONIETTO et al., 2001).

Em relação ao número de raízes menores índices de emissão de raízes ocorreram nas estacas de $P$. mikanianum que não foram submetidas ao tratamento com AIB, tanto nas estacas mantidas na areia, apresentando 1,9 raízes em média, quanto àquelas mantidas no substrato constituído por vermiculita, com 2,5 raízes. Em estacas de macieira (Malus pumila) PEDROTTI e VOLTOLINI (2001) não observaram diferenças estatísticas quando comparados os tratamentos com 500; 1000 e 1500 $\mathrm{mg} \mathrm{L}^{-1}$ de AIB, sendo que o número de raízes emitidas variou de 6 a 8 , e a testemunha produziu em média 3,5 raízes por estaca, valores esses inferiores àqueles obtidos nas miniestacas que foram tratadas com AIB. Mais recentemente, BASTOS et al. (2005), não observaram enraizamento e formação de calos nas estacas lenhosas de caquizeiro (Diospyros kaki) e associaram tal resultado à baixa quantidade de auxina exógena utilizada nas estacas, uma vez que, em alguns cultivares, a presença de AIB aumentou a taxa de sobrevivência, a exemplo da cultivar Giombo, que teve um aumento de $28,65 \%$ de sobrevivência de suas estacas quando tratadas com $3000 \mathrm{mg} \mathrm{L}^{-1}$ de AIB, mas uma diminuição de sobrevivência cujo valor foi de $38,44 \%$ quando essas foram tratadas com $6000 \mathrm{mg} \mathrm{L}^{-1}$. Estes resultados provam que, em concentrações adequadas, o ácido indol-butírico promove enraizamentoem estacas.

MORE e KHALATKAR (1988) citam que a concentração subótima de AIB pode não alcançar o nível requerido de auxina para a iniciação radicular, mas concentrações supraótimas inibem o enraizamento, devido ao aumento da síntese de etileno, induzido pela auxina, o que restringe a divisão e elongações celulares.

Para o substrato constituído por vermiculita (Figura $1 \mathrm{C}$ ), o comprimento médio de raízes em estacas de $P$. Mikanianum mostrou-se com diferenças estatísticas significativas, atingindo comprimentos médios de 6,37 e $8,76 \mathrm{~cm}$ quando tratadas nas concentrações de AIB de 1000 e 1500 $\mathrm{mg} \mathrm{L}^{-1}$, respectivamente. Este resultado remete a comprovação da eficiência da auxina muito mais no processo de indução de raízes do que no seu crescimento.

Observou-se, nos dois substratos utilizados no presente trabalho, que o comprimento de raízes nas estacas de $P$. mikanianum aumentou conforme aumentava a concentração de AIB (Figura 
1C). O mesmo ocorreu nas estacas de aceroleira (Malpighia emarginata), sendo que o maior comprimento da raiz $(9 \mathrm{~cm})$ foi obtido na concentração de $2800 \mathrm{mg} \mathrm{L}^{-1}$ de AIB em estacas com dois pares de folhas, utilizando vermiculita como substrato (GONTIJO et al., 2003).

O comprimento das raízes das estacas mantidas no substrato constituído por areia apresentou-se com um maior comprimento significativo nas raízes formadas nas estacas de $P$. mikanianum no substrato constituído por areia (Figura 1C). Portanto nos remete ao fato de que ocorreu interação entre o substrato e o comprimento de raízes em estaquia de plantas semilenhosa de duas espécies de guaco (Mikania glomerata e M. laevigata). O substrato constituído por solo foi inferior à casca de arroz carbonizada e areia em relação ao desenvolvimento do sistema radicial (LIMA et al. 2003). Provavelmente, o crescimento depende de condições físicas e químicas do substrato utilizado e das substâncias de reserva que a planta utiliza para a divisão e elongação celular das raízes.

O substrato constituído por areia pode ter afetado o comprimento de raízes de $P$. Mikanianum, sendo que os melhores resultados foram obtidos no tratamento com $1500 \mathrm{mg} \mathrm{L}^{-1}$ cujo valor do comprimento médio da raiz foi de $8,76 \mathrm{~cm}$, valor este superior ao das estacas cultivadas na vermiculita.

Mesmo foi encontrado em estacas de Prunus cerasifera, RAMOS et al. (2003) verificaram que a maior média de comprimento das raízes foi observada com a utilização do substrato constituído por vermiculita, obtendo-se comprimento médio das raízes na ordem de $1,97 \mathrm{~cm}$, enquanto a areia proporcionou apenas $1,07 \mathrm{~cm}$.

A quantidade de brotações nas estacas de $P$. Mikanianum não foi influenciada significativamente pelos substratos e pelas concentrações AIB, como mostram a FIGURA 1D. Talvez a concentração de AIB foi pequena para interferir nessa variável, como foi verificado no trabalho de MENDONÇA et al. (2002). Eles observaram que estacas de cupuaçuzeiro (Theobroma grandiflorum) só ocorreram aumento significativo a partir da concentração de $4000 \mathrm{mg} \mathrm{L}$ ${ }^{1}$ de AIB ocorreu aumento significativo de número de brotos e raízes por estaca.

O pequeno número de brotações observada nas estacas de $P$. mikanianum pode ser atribuído aos substratos utilizados, ou ainda pelo tempo em que foram mantidas no substrato, pois, em estudo com estacas de acerola (Malpighia emarginata), LOPES et al. (2003) observaram a menor porcentagem de brotações $(33,33 \%)$ utilizando os substratos vermiculita e $32,91 \%$ de brotações com areia, sendo superados significativamente pelos substratos terra+areia+esterco, com $74,16 \%$ e pó de xaxim, com $50,41 \%$. Os autores observaram ainda aumento de brotações aos 25 dias em decorrência do aumento das concentrações de AIB.
BARDALES (1997), utilizando como substrato areia lavada e solo, verificou que não houve efeito significativo na emissão de brotos e enraizamento em estacas de Theobroma grandiflorum enraizadas, quando estas foram tratadas com ácido indolbutírico. TAVARES et al. (1995), não verificaram influência do regulador AIB nas brotações em estacas de goiabeira (Psidium guajava) com cinza de casca de arroz como substrato.

Quanto ao comprimento das brotações, foi observado diferença significativa entre os tratamentos, tanto em relação ao substrato quanto às concentrações de $\mathrm{AIB}$, resultados que podem ser verificados na Figura $1 \mathrm{E}$. O tratamento com 0 , 1000 e $1500 \mathrm{mg} \mathrm{L}^{-1}$ de AIB e areia como substrato, induziu maiores alturas médias de 3,58, 3,5 e 3,9 $\mathrm{cm}$, respectivamente, sendo que a maior média de brotação para as estacas submetidas ao substrato vermiculita foi de $2,3 \mathrm{~cm}$ nas estacas submetidas uma concentração de $1500 \mathrm{mg} \mathrm{L}^{-1}$ de AIB. A resposta quanto ao substrato, encontrada no presente trabalho, difere daquela encontrada em estacas de acerola (Malpighia emarginata), nas quais os menores tamanhos de brotos $(0,44 \mathrm{~cm})$ foram obtidos em estacas mantidas no substrato constituído por areia, sendo este valor superado pelos brotos formados em substrato constituído por vermiculita, com $0,52 \mathrm{~cm}$ de comprimento, não sendo a diferença significativa entre esses valores (LOPES et al., 2003). O efeito negativo do substrato vermiculita está no reduzido tamanho das brotações que também pôde ser observada no trabalho realizado por BIASI e COSTA (2003), que encontrou diferença quanto ao comprimento dos brotos de Lippia alba: o maior valor foi obtido com a utilização de substrato Plantmax ${ }^{\circledR}$, superando a vermiculita.

Considerando que, em geral autores citam como substratos ideais para o enraizamento a areia e a vermiculita, o Plantmax ${ }^{\circledR}$ vem a ser uma nova alternativa para futuros experimentos com enraizamento, pois se trata de um substrato que mais se aproxima dos valores de espaços de aeração considerados ideais (SKREBSKY et al., 2006), valores estes entre 20 e $30 \%$, lembrando que a aeração é responsável pela manutenção de oxigênio nas raízes (DE BOODT e VERDONCK, 1972), o que pode trazer novos resultados.

\section{CONCLUSÕES}

O presente estudo mostrou que estacas de Piper mikanianum cultivadas em substrato constituído por vermiculita são capazes de formar maior número de folhas, raízes e brotações, cujos valores foram proporcionais ao aumento da concentração de AIB, devido a boa retenção de água e ótimo espaço de aeração.

\section{REFERÊNCIAS}

1. ABREU, A. M. De; SEVEGNANI, I.; MACHICADO, A.R.; ZIMERMANN, D.; REBELO, R. A. Piper mikanianum (Kinth) Steudel from Santa Catarina, Brasil - a new source of safrole. Journal of Essential Oil Research, v. 14, p. 361-363, 2002. 2. ALVARENGA,L.R.; CARVALHO,V.D. Uso de substâncias promotoras de enraizamento de estacas frutíferas. Informe Agropecuário, v. 9, n. 101, p. 47-55, 1983. 
PESCADOR, R. et al. Estaquia de pariparoba...

3. BARDALES, N.G. Efeito do ácido indolbutírico no enraizamento de estacas de cupuaçuzeiro. In: SEMINÁRIO DE INICIAÇÃO CIENTÍFICA DA UFAC, 7., 1997, Rio Branco. Anais. Rio Branco: UFAC/PROPEG/COAP, 1997. p. 90.1 CDROM.

4. BASTOS, D.C.; PIO, R.; FILHO, J.A.S.; LIBARDI, M.N.; ALMEIDA, L.F.P.; ENTELMANN F.A. Enraizamento de estacas lenhosas e herbáceas de cultivares de caquizeiro com diferentes concentrações de ácido indolbutírico. Revista Brasileira de Fruticultura, v. 27, n. 1, p. 182-184, 2005.

5. BIASI, L.A.; COSTA, G. Propagação vegetativa de Lippia alba. Ciencia Rural, v. 33, n. 3, p. 455-459, 2003.

6. BLAZICH, F.A. Chemicals and formulations used to promote adventitious rooting. In: DAVIES, T.D.; HAISSIG, B.E.; SANKHLA, N. (Eds.). Adventitious root formation in cuttings. Portland: Dioscorides Press, 1987. p. 132-149. (Advances in Plant Sciences Series, 2).

7. CALDERARI, M.T.; BRIGHENTE, I.M.C. Estudo dos óleos essenciais de Piperaceae do Vale do Itajaí em Santa Catarina. Florianópolis, 2002. 99 f. Dissertação (Mestrado em Química) - Departamento de Química, Universidade Federal de Santa Catarina.

8. CHUNG, D.Y.; LEE, K.J. Effects of clones, ortet age, crown position, and rooting substance upon the rooting of cuttings of Japanese larch (Larix leptolepis S. et Z. Gordon). Forestry Genetics Research Institute, v. 83, n. 2, p. 205210, 1994

9. DE BOODT, M.; VERDONCK, O. The physical properties of the substrates in horticulture. Acta Horticulturae, v.26, p.37-44, 1972

10. DUTRA, L.F.; SCHWENGBER, J.E.; TONIETTO, A. Enraizamento de estacas de ramos de pessegueiro (Prunus persica (L) Bastsch). Revista Brasileira de Agrociência, v. 5, n. 2, p. 93-95, 1999.

11. EHLERT, P.A.D.; LUZ, J.M.Q.; INNECCO, R. Propagação vegetativa da alfavaca-cravo utilizando diferentes tipos de estacas e substratos. Horticultura Brasileira, v. 22, n. 1, p. 10-13, 2004.

12. GOMES, A.L. Propagação clonal: princípios e particularidades. Vila Real: Universidade de Trás-os-Montes e Alto Douro, 1987. 69 p. (Série Didáctica, Ciências Aplicadas, 1).

13. GONTIJO, T.C.A.; RAMOS, J.D.; MENDONÇA, V.; PIO, R.; NETO, S.E.A.; CORRÊA, F.L.O. Enraizamento de diferentes tipos de estacas de aceroleira utilizando ácido indolbutírico. Revista Brasileira de Fruticultura, v. 25, n. 2, p. 290 292, 2003.

14. GUIMARÃES, E.F.; VALENTE, M.C. Piperáceas. Flora llustrada Catarinense. 2002. 104 p.

15. HARTMANN, H.T.; KESTER, D.E.; DAVIES JR., F.T.; GENEVE, R.L. Plant propagation: principles and practices. 6. ed. New Jersey: Prentice-Hall, 1997. 770 p.

16. HOFFMANN, A.; PASQUAL, M.; CHALFUN, N.N.J. Efeito de substratos na aclimatização de plantas micropropagadas do porta-enxerto de macieira "marubakaido". Ciência e Agrotecnologia, v. 25, n. 2, p. 462-467, 2001.

17. KERBAUY, G.B. Fisiologia vegetal. Rio de Janeiro: Guanabara Koogan, 2004. 452 p.

18. LIMA, N.P.; BIASI, L.A. ; ZANETTE, F.; NAKASHIMA, T. Estaquia semilenhosa e análise de metabólitos secundários de guaco (Mikania glomerata Sprengel e Mikania laevigata Schultz Bip. Ex Baker). Revista Brasileira de Plantas Medicinais, v. 5, n. 2, p. 47-54, 2003.

19. LOACH, K. Hormone aplications and adventious root formation in cuttings - a cutical review. Acta Horticulturae, n. 227, p. 126-133, 1988.

20. LOPES, J.C.; ALEXANDRE, R.S.; SILVA, A.E.C. e RIVA, E.M. Influência do ácido indol-3-butírico e do substrato no enraizamento de estacas de acerola. Revista Brasileira de Agrociência, v. 9, n. 1, p. 79-83, 2003.

21. MENDONÇA, H.A. de; GONDIM, T.M S. ; NEGREIROS, J.R.S.; AZEVEDO, F.F. Efeito do ácido indolbutírico no enraizamento de estacas de cupuaçu. In: CONGRESSO BRASILEIRO DE FRUTICULTURA, 17., 2002. Anais. Belém: Embrapa Amazônia Oriental, 2002. CD-ROM.

22. MORE, V.N.; KHALATKAR, A.S. Effect of giberellica acid, kinetin and indobutyric acid on propagation in Diffenbachia pict. Acta Horticulturae, n. 226, p. 473-478, 1988.

23. PEDROTTI, E.L.; VOLTOLINI, J.A. Enraizamento ex vitro e aclimatização do porta-enxerto de macieira M.9. Revista Brasileira Fruticultura, v. 23, n. 2, p. 234-239, 2001.

24. PIMENTA, A.C.; ZUFFELLATO-RIBAS, K.C.; OLIVEIRA, B.H.; CARPANEZZI, A.A.; KOEHLER, H.S. Interações entre reguladores vegetais, épocas do ano e tipos de substrato no enraizamento de estacas caulinares de Sapium glandulatum (Vell.) Pax. (Pau-de-leite). Boletim de Pesquisa Florestal, n. 50, p. 53-67, 2005.

25. RAMOS, J.D.; MATOS, L.E.S.; GONTIJO, T.C.A.; PIO, R.; JUNQUEIRA, K.P.; SANTOS, F.C. Enraizamento de estacas herbáceas de 'mirabolano' (Prunus cerasifera Ehrn) em diferentes substratos e concentrações de ácido indolbutírico. Revista Brasileira de Fruticultura, v. 25, n. 1, p. 189-191, 2003.

26. RIZZINI, C.T.; MORS, W.B. Botânica econômica brasileira. 2. ed. rev. atual. Rio de Janeiro: Âmbito Cultural, 1995. $248 \mathrm{p}$.

27. SILVA, R.P. da; PEIXOTO, J.R.; JUNQUEIRA, N.T.V. Influência de diversos substratos no desenvolvimento de mudas de maracujazeiro-azedo (Passiflora edulis Sims f. flavicarpa DEG). Revista Brasileira de Fruticultura, v. 23, n. 2, p. 377-381, 2001.

28. SKREBSKY, E.C.; NICOLOSO, F.T.; MALDANER, J. Substrates in the acclimatization of Pfaffia glomerata (Spreng.) Pedersen produced in vitro under different levels of sucrose. Ciência Rural, v. 36, n. 5, p. 1416-1423, 2006.

29. TAIZ, L.; ZEIGER, E. Fisiologia vegetal. 3. ed. Porto Alegre: Artmed, 2004. 719 p.

30. TAVARES, M.S.W.; KERSTEN, E.; SIEWERDT, F. Efeitos do ácido indolbutírico e da época de coleta no enraizamento de estacas de goiabeira (Psidium guajava L.). Scientia Agricola, v. 52, n. 2, p.310-317, 1995.

31. TILLMANN, M.A.A.; CAVARIANI, C.; PIANA, Z.; MINAMI, K. Comparação entre diversos substratos no enraizamento de estacas de cróton (Codiaeum variegatum). Scientia Agricola, v. 51, n. 1, p. 17-20, 1994.

32. TONIETTO, A.; DUTRA, L.F.; KERSTEN, E. Influência do ácido indolbutírico e etefhon no enraizamento de estacas de pessegueiro (Prunus persica (L) Batsch.). Ciência Rural, v. 27, n. 4, p. 567-569, 1997.

33. VOLTOLINI, J.A.; NUNES, J.C.O.; PEDROTTI, E.L. Crescimento de plântulas micropropagadas do porta-enxerto de macieira m7 (Malus sylvestris Mill.) após a aclimatização. In: CONGRESSO BRASILEIRO DE FRUTICULTURA, 17., 2002. Anais. Belém: Embrapa Amazônia Oriental, 2002. CD-ROM.

34. WENDLING, I. XAVIER, A; GOMES, J.M.; PIRES, I.E.; ANDRADE, H.B. Efeito do regulador de crescimento AIB na propagação de clones de Eucalyptus spp. por miniestaquia. Revista Árvore, v. 24, n. 2, p. 187-192, 2000.

35. XAVIER, A.; COMÉRIO, J. Microestaquia: uma maximização da micropropagação de Eucalyptus. Revista Árvore, v. 20, n. 1, p. 9-16, 1996. 